\title{
The effect of pegylated human recombinant leptin (PEG-OB) on neuroendocrine adaptations to semi-starvation in overweight men
}

\author{
Chris J Hukshorn, Paul P C A Menheere ${ }^{1}$, Margriet S Westerterp-Plantenga and Wim H M Saris \\ Nutrition and Toxicology Research Institute Maastricht (NUTRIM), Department of Human Biology, Maastricht University, PO Box 616, \\ $6200 \mathrm{MD}$ Maastricht, The Netherlands and ${ }^{1}$ Department of Clinical Chemistry, University Hospital Maastricht, PO Box 5800,6202 AZ Maastricht, \\ The Netherlands \\ (Correspondence should be addressed to C J Hukshorn; Email: c.hukshorn@hb.unimaas.nl)
}

\begin{abstract}
Objective: Starvation induces a complex neuroendocrine response in humans thought to have evolved to defend against reduced energy intake. The drop in leptin levels observed during fasting has been implicated as a factor that triggers this adaptive response. To explore this hypothesis, we executed a randomized, double-blind, placebo-controlled study to investigate whether elevated leptin levels using long-acting pegylated human recombinant leptin (PEG-OB) influenced the neuroendocrine responses to semi-starvation in human subjects.

Design: Twenty-four overweight male subjects (mean \pm S.E.M.; $34.8 \pm 1.3 \mathrm{yrs} ; 28.8 \pm 0.5 \mathrm{~kg} / \mathrm{m}^{2}$ ) were prescribed a very low energy diet $(2.1 \mathrm{MJ} /$ day $)$ to induce a state of semi-starvation for the next 46 days. In addition, all subjects received a weekly treatment of $80 \mathrm{mg}$ PEG-OB or matching placebo. Hormone measurements were performed throughout the study period and included 5-h frequent hormone samplings and 24-h urine collections.

Results: Weekly subcutaneous administration of PEG-OB led to significant additional weight loss $(2.8 \mathrm{~kg})$ but it did not reverse the fasting-induced changes in the thyroid, corticotropic, somatotropic axes and sympathetic nervous system activity. However, after adjustment for weight loss, the drop in mean luteinizing hormone levels was attenuated in the PEG-OB group compared with the placebo group.

Conclusions: These results suggest that a reduced level of leptin accompanying food restriction might be a component of the fasting-induced neuroendocrine inhibition of the human reproductive axis.
\end{abstract}

European Journal of Endocrinology 148 649-655

\section{Introduction}

Starvation or severe energy restriction rapidly evokes several neuroendocrine adaptive responses in humans. These responses are thought to have survival value in periods of inadequate energy intake. Among these neuroendocrine adaptations is a suppression of both the reproductive and thyroid axes while selected components of the corticotropic and somatotropic axes are stimulated $(1,2)$. The mechanisms that trigger these adaptive responses to energy restriction are still not clear.

Leptin, the protein hormone encoded by the $o b$ gene, is primarily secreted from adipose tissue and plays an important role in body weight homeostasis by regulating food intake and energy expenditure $(3-5)$. Serum leptin concentrations are directly proportional to adipocyte mass and are reduced in humans and animals that have lost body fat, or are energy-restricted (6).
Some investigators have suggested that leptin has a broader physiological role and evolved as a mediator of the adaptations to fasting, and thus promotes the chances of survival during periods of starvation $(2,7)$. In favor of this hypothesis is the fact that during fasting leptin levels drop rapidly and out of proportion to fat mass changes (8). In addition, leptin administration to rodents attenuates many of these fasting-induced neuroendocrine changes in gonadal, adrenal, and thyroid axes $(7,9)$. In male non-human primates conflicting reports exist regarding the effect of peripheral infusion of leptin during a short-term fast. Reversal of the inhibitory effects of fasting on gonadotropin release occurred in one study while no effect was found in two others (10-12). In one study, intravenous replacement with homologous leptin did not reverse the acute changes in growth hormone $(\mathrm{GH})$ and cortisol secretion observed with fasting in the adult male macaque (12). 
One approach to study whether the neuroendocrine effects of leptin administration to animals during fasting can be extended to humans is to administer exogenous leptin in conditions associated with a (relative) deficiency or absence of leptin, such as during severe energy restriction.

Therefore, we undertook a randomized, double-blind, placebo-controlled study to investigate whether elevated leptin levels using long-acting pegylated recombinant leptin (PEG-OB) were able to attenuate the neuroendocrine adaptations to semi-starvation induced by a very low energy diet (VLED) in healthy overweight male subjects.

\section{Subjects and methods}

\section{Subjects}

Twenty-four healthy overweight male volunteers were recruited by local advertizing, screened and enrolled in the study after execution of written informed consent. The study was approved by the Medical Ethical Committee of the Maastricht University. Overweight and mildly obese men aged $18-45 \mathrm{yrs}$ and with a body mass index (BMI) between 25 and $32 \mathrm{~kg} / \mathrm{m}^{2}$ were eligible for inclusion. Additional inclusion criteria were: detailed medical and psychiatric histories and a physical examination with negative findings, including a normal adult sexual maturation, a normal 12-lead resting electrocardiogram, no medical condition present, no use of prescription medication, no smoking and no transmeridian travel in the previous 4 weeks. Each participant had normal biochemical tests of renal, hepatic, metabolic and hematological function, and morning fasting serum concentrations of insulin, cortisol, insulin-like growth factor-1 (IGF-1), thyroid stimulating hormone (TSH), prolactin (PRL), and total testosterone within the normal ranges. Subjects with a history or presence of drug abuse or alcoholism, atopy or hypersensitivity to pegylated proteins and with a weight loss of more than $3 \mathrm{~kg}$ in the previous 3 months were excluded from the study.

\section{Study design}

This single center trial had a prospective, randomized, double-blind, placebo-controlled group design. After screening, 24 subjects were selected and enrolled in the trial. The study was divided into three phases: a) baseline characterization (day $-14,-8$ and 1); b) PEG-OB or placebo treatment and a VLED for 46 days (day 1 to 46); and c) follow-up for 2 weeks (day 50 and 57). Baseline characterization consisted of a 5 -h frequent blood sampling protocol (day - 14) and a 24-h urine collection (day -8) to measure the 24-h excretion of norepinephrine (NE) performed in the 2 weeks before the start of the diet and treatment period. All subjects were asked to maintain a constant body weight until the beginning of the diet and treatment phase and their normal levels of physical activity throughout the study period. Subjects were stratified and matched into pairs according to age, BMI, fasting serum leptin and insulin concentration to achieve balanced treatment groups. Randomization numbers for subjects were generated and incorporated into the double-blind labeling by an independent third party. At the start of the treatment period (day 1) all subjects were prescribed a VLED to induce a state of semi-starvation for the next 46 days. The VLED (Modifast, Novartis, Breda, The Netherlands) provides $2.1 \mathrm{MJ}$ daily and is a protein enriched formula diet (containing 44,14 , and $42 \%$ of energy as protein, fat and carbohydrate, respectively). The dietary prescription was discussed every week with a dietician. Adherence to the diet was confirmed by measurements of body weight loss. Treatment consisted of either weekly $80 \mathrm{mg}$ PEG-OB $\left(8 \mathrm{ml}, 10 \mathrm{mg} \mathrm{ml}^{-1}\right.$; produced and provided by Hoffmann-La Roche Inc., Nutley, New Jersey) or matching placebo $(8 \mathrm{ml})$ given s.c. in the para-umbilical region during the VLED period. Subjects returned in a fasting state on day $8,15,22,29,36$, and 43 to the laboratory to receive treatment after weight and vital signs (pulse, respiratory rate, and blood pressure) were recorded. Blood samples were drawn for safety laboratory tests and hormone measurements on day $1,8,15$, 25 , and 46. On day 24 the 24-h urine collection and on day 25 the 5-h frequent blood sampling protocol were repeated. After the treatment period (day 46) all subjects received less formula diet and were instructed to supplement this with a free choice of habitual food items in order to gradually increase their energy intake over the next 2 weeks. Vital signs and body weight during this follow-up period were measured on day 50 and 57. Safety was monitored by documentation of adverse events and recording of vital signs at each visit. In addition, urine analysis and routine measurements of serum chemistry and blood cell counts were conducted regularly throughout the study. Standard clinical chemistry and blood cell counts were conducted at the certified central laboratory of the University Hospital Maastricht, The Netherlands.

\section{PEG-OB}

Recombinant methionyl human leptin has a reported average terminal half-life of approximately $4 \mathrm{~h}$ in humans, which requires daily administration to obtain sustained blood levels (13). Modification of proteins through covalent linkage of polyethylene glycol polymers to the protein has resulted in reduced immunogenicity and increased serum half-life for a number of proteins (14). Recombinant native human leptin, expressed and purified from Escherichia coli, was chemically conjugated to a species of branched polyethylene glycols (PEGs) with an average molecular weight of $42 \mathrm{kDa}$ in a 1:1 ratio. The result was a globular PEG-native human leptin polymer (PEG-OB) with 
increased molecular size. PEG-OB at a concentration of $10 \mathrm{mg} / \mathrm{ml}$ was placed in sterile glass vials containing $1.3 \mathrm{ml}$. Preclinical studies with PEG-OB indicate an extended half-life $(>48 \mathrm{~h})$ and efficacy for reduction of food intake and body weight in animals (15). Our previous study in obese male subjects clearly showed sustained elevated blood levels following weekly s.c. dosing of PEG-OB in humans. Mean peak serum PEG-OB concentrations were achieved $72 \mathrm{~h}$ after dosing, followed by a return to the elevated pre-dose levels after 1 week (16).

\section{Hormone measurements}

Venous blood was sampled on day 1, 8, 15, 25, and 46 after an overnight fast and allowed to clot for $20 \mathrm{~min}$ at room temperature. Immediately after clotting the samples were put on ice and serum was extracted by centrifugation. The sera obtained were frozen in liquid nitrogen and stored at $-80^{\circ} \mathrm{C}$ for later measurements of serum cortisol, insulin, IGF-1, free 3,5,3'-triiodothyronine $\left(\mathrm{FT}_{3}\right)$, and free thyroxine $\left(\mathrm{FT}_{4}\right)$. Mean 5 -h hormone levels were determined using a 5-h frequent blood sampling protocol. In both the fed (day - 14) and the energy restricted (day 25) states, blood sampling was carried out at 10-min intervals for $5 \mathrm{~h}$ beginning at $0800 \mathrm{~h}$, at least $1 \mathrm{~h}$ after venapuncture. Blood was withdrawn through an indwelling i.v. catheter placed into an antecubital vein and collected with aprotinin (Trasylol, 10000 Kallikrein inhibiting U/l; Bayer, Etobicoke, Canada). Subjects remained in bed during sampling and daytime naps were not allowed. Serum concentrations of cortisol, $\mathrm{GH}$, luteinizing hormone (LH), follicle stimulating hormone (FSH), TSH, PRL, total testosterone, sex hormone binding protein (SHBG) and albumin were assayed in a single 5 -h pool of serum.

\section{Assays}

The serum concentrations of cortisol, insulin, IGF-1, $\mathrm{FT}_{3}, \mathrm{FT}_{4}, \mathrm{GH}, \mathrm{LH}, \mathrm{FSH}, \mathrm{TSH}, \mathrm{PRL}$, total testosterone, SHBG and albumin were all measured at the certified central laboratory of the University Hospital Maastricht. Serum cortisol was measured with a luminescence enzyme-immunoassay ((LEIA), Immulite 200, DPC, Los Angeles, USA), which has a sensitivity of $25 \mathrm{nmol} / \mathrm{l}$ and a reproducibility better than $10 \%$. Serum insulin was measured by an immunofluorimetric sandwich assay ((IFMA), Autodelfia, Perkin Elmer, Turku, Finland), which has a sensitivity of $1.4 \mathrm{mU} / \mathrm{l}$ and a reproducibility better than $6 \%$. Serum IGF-1 was measured by IRMA (Nichols Institute Diagnostics, San Juan Capistrano, USA), which has a sensitivity of $17 \mathrm{ng} / \mathrm{l}$ and a reproducibility better than $15 \% . \mathrm{FT}_{3}$ and $\mathrm{FT}_{4}$ were measured by two-step fluoroimmunoassay ((FIA), Autodelfia), which has a sensitivity of $0.04 \mathrm{pmol} / \mathrm{l}$ and a reproducibility better than $4 \%$ for $\mathrm{FT}_{3}$ and a sensitivity of $1.3 \mathrm{pmol} / \mathrm{l}$ and a reproducibility better than $4 \%$ for $\mathrm{FT}_{4}$. Serum GH was measured by IFMA, which has a sensitivity of $0.1 \mathrm{mU} / \mathrm{l}$ and a reproducibility better than $7 \%$. Serum LH was measured by IFMA, which has a sensitivity of $0.01 \mathrm{U} / \mathrm{l}$ and a reproducibility better than $3 \%$. Serum FSH was measured by IFMA, which has a sensitivity of $0.2 \mathrm{U} / \mathrm{l}$ and a reproducibility better than $10 \%$. Serum TSH was measured by IFMA, which has a sensitivity of $0.012 \mathrm{mU} / \mathrm{l}$ and a reproducibility better than $2 \%$. Serum PRL was measured by IFMA, which has a sensitivity of $0.0005 \mathrm{U} / \mathrm{l}$ and a reproducibility better than $6 \%$. Total serum testosterone was measured by radioimmunoassay (DPC), which has a sensitivity of $0.7 \mathrm{nmol} / \mathrm{l}$ and a reproducibility better than $10 \%$. Serum SHBG was measured by LEIA, which has a sensitivity of $1 \mathrm{nmol} / \mathrm{l}$ and a reproducibility better than $4.5 \%$. Free testosterone was calculated from serum total testosterone, SHBG, and albumin according to Swinkels et al. $(17,18)$ using the equilibrium constants of testosterone to SHBG and albumin to testosterone derived from Dunn et al. (19). Urinary NE was determined by HPLC using the ClinRep kit from Recipe (Munich, Germany). Total leptin concentrations (endogenous leptin plus PEG-OB) were measured according to the method described previously (16).

\section{Statistics}

Data were analyzed using two-factor repeatedmeasures ANOVA to compare differences in parameters across the two groups over time. When significant differences were found, a post hoc Scheffe's procedure was used to determine the location of the difference. A multiple-linear regression model with the percentage change in 5-h mean hormone concentrations from baseline as the dependent variable and the percentage change in weight and treatment status as independent variables was used to analyze the difference in percentage change in 5-h mean hormone concentrations from baseline between both treatment groups, adjusted for the independent variables. All statistical tests were two-sided and significance was defined as $P<0.05$. All data are presented as means \pm s.E.M., unless otherwise indicated.

\section{Results}

The characteristics of the subjects before the intervention are presented in Table 1 . The parameters used to match subjects into pairs were not different and balanced treatment groups were achieved. The baseline hormone levels of the 12 subjects randomized to each treatment group were similar. All subjects in the trial were of Caucasian origin. Two subjects of the placebo group dropped out voluntarily after 1 week because they were not able to maintain the strict VLED 
Table 1 Baseline characteristics of the 24 subjects at the screening.

\begin{tabular}{lcc}
\hline Characteristic & Placebo $(n=12)$ & PEG-OB $(n=12)$ \\
\hline Age (years) & $34.9 \pm 1.3(24.0-40.0)$ & $34.6 \pm 1.2(26.0-41.0)$ \\
Weight $(\mathrm{kg})$ & $95.0 \pm 3.2(77.2-113.9)$ & $97.1 \pm 1.8(87.5-106.6)$ \\
BMI $\left(\mathrm{kg} / \mathrm{m}^{2}\right)$ & $28.6 \pm 0.5(25.2-31.2)$ & $28.9 \pm 0.4(27.3-31.2)$ \\
Leptin $(\mathrm{ng} / \mathrm{ml})$ & $7.3 \pm 0.9(4.3-16.3)$ & $7.0 \pm 0.8(2.3-12.9)$ \\
Insulin $(\mathrm{mU} / \mathrm{l})$ & $9.7 \pm 1.8(4.0-26.0)$ & $7.8 \pm 1.3(1.9-17.0)$ \\
Cortisol $(\mathrm{nmol} / \mathrm{l})$ & $333 \pm 26(181-478)$ & $349 \pm 34(208-551)$ \\
IGF-1 $(\mathrm{ng} / \mathrm{ml})$ & $166 \pm 11(120-260)$ & $177 \pm 11(122-244)$ \\
TSH $(\mathrm{mU} / \mathrm{l})$ & $1.6 \pm 0.1(0.9-2.5)$ & $1.5 \pm 0.2(0.7-2.5)$ \\
PRL (U/l) & $0.18 \pm 0.02(0.12-0.30)$ & $0.17 \pm 0.02(0.09-0.31)$ \\
Total testosterone $(\mathrm{nmol} / \mathrm{l})$ & $15.4 \pm 1.0(9.0-21.4)$ & $15.3 \pm 0.8(10.0-21.7)$ \\
\hline
\end{tabular}

No statistical significant differences were found between both groups.

Data are presented as means \pm S.E.M.

regime. However, baseline characteristics of the two groups remained comparable (data not shown). As this study was a part of a greater study, results on body weight, body composition, energy expenditure and appetite have been published elsewhere (20). In summary, at the end of the treatment period (day 46), weight loss was $14.6 \pm 0.8 \mathrm{~kg}$ in the PEG-OB group, compared with $11.8 \pm 0.9 \mathrm{~kg}$ in the placebo group $(P=0.027)$. Significant reductions in appetite were observed in the PEG-OB group however.

Table 2 shows the effect of energy restriction and treatment on cortisol, $\mathrm{FT}_{3}, \mathrm{FT}_{4}, \mathrm{IGF}-1$, insulin and total leptin measured on day $1,8,15,25$, and 46 . In the first 3 weeks of the study cortisol levels increased significantly from initial values in the PEG-OB group. However, the rise of cortisol levels in the placebo failed to reach significance. At the end of the treatment period (day 46) cortisol fell below baseline levels in both groups. $\mathrm{FT}_{3}$ declined significantly in the first 3 weeks of study in both groups but the fall remained significant in the PEG-OB group on day 46 only. $\mathrm{FT}_{4}$ levels were increased in the placebo and PEG-OB groups during the whole study, but only on days 8 and 15 was this rise significantly different from the baseline. IGF-1 declined similarly in both groups to levels well below the normal range during the study and reached a minimum on day 25. Insulin levels declined from baseline in both groups and remained significantly reduced throughout the study. Urinary excretion of NE fell from $54.5 \pm 3.4 \mu \mathrm{g} / 24$-h to $42.3 \pm 3.5 \mu \mathrm{g} / 24-\mathrm{h}$ in the placebo group and from $51.5 \pm 4.3 \mu \mathrm{g} / 24-\mathrm{h}$ to $44.6 \pm 5.4 \mu \mathrm{g} / 24-\mathrm{h}$ in the PEG-OB group. No significant differences were observed in levels of cortisol, $\mathrm{FT}_{3}, \mathrm{FT}_{4}$, IGF-1, insulin and 24-h urinary NE excretion between treatment groups over time.

Food restriction for 6 weeks by means of a VLED reduced circulating leptin levels by $72 \%$ to $2.0 \pm 0.2 \mathrm{ng} / \mathrm{ml}$ in the placebo group $(P<0.001)$. Following weekly s.c. dosing, sustained serum levels of total leptin (endogenous leptin plus PEG-OB), measured just before the next dose on day 8 and 15 , ranging from 950 to $3700 \mathrm{ng} / \mathrm{ml}$ were observed. Peak total leptin concentrations on day 25 and 46, measured $72 \mathrm{~h}$ after s.c. injection, ranged from 2300 to $6050 \mathrm{ng} / \mathrm{ml}$.

The 5-h mean concentrations of serum cortisol, GH, LH, FSH, TSH, PRL, total testosterone, SHBG, albumin and estimated free testosterone on both study days (days -14 and 25) for the two treatment groups are shown in Table 3. Serum 5-h mean cortisol, TSH, FSH and albumin levels were unchanged by energy restriction and treatment in both groups. The 3 weeks of semi-starvation resulted in a more than 4-fold increase in the mean (5-h) serum GH concentrations and an approximately 2-fold increase in mean SHBG levels in all subjects. In contrast to the group receiving PEG-OB, mean LH and PRL levels decreased significantly in the placebo group. Mean total testosterone levels increased significantly in the PEG-OB treatment group but remained unaltered in the placebo group. Calculated free testosterone concentrations declined significantly in both the placebo and PEG-OB groups. There was no significant difference in the delta or percent change from baseline of 5-h mean concentrations of serum cortisol, GH, LH, FSH, TSH, PRL, total testosterone, SHBG, albumin, and estimated free testosterone between the groups.

A multiple-linear regression model with the percentage change in 5-h mean hormone concentrations from baseline as a dependent variable and the percentage change in weight and treatment status as independent variables was used to analyze the differences between both treatment groups, defined by the binary variable group. The percentage change in 5-h mean LH concentrations of the PEG-OB group, plotted as a function of percentage change in weight, resulted in a positive relationship, i.e. a regression line that was superimposed on the regression line of the placebo group (Fig. 1). The regression line of the PEG-OB group was significantly different from the regression line of the placebo group $(P=0.03)$. The percentage change in 5-h mean LH concentrations adjusted for percentage weight loss resulted in a reduced decrease in percentage change in 5-h mean LH concentrations for the PEG-OB 
group compared with the placebo group. For the complete study sample, both independent variables accounted for $31 \%$ of the variance in mean $5-\mathrm{h}$ serum LH concentrations.

\section{Discussion}

We previously reported that exogenous leptin induces additional weight loss in humans under severe energy-restricted conditions by reducing appetite. In the present report, we studied the effect of elevated leptin levels using long-acting PEG-OB on the neuroendocrine responses to severe energy-restriction in human subjects.

Introducing a state of semi-starvation in this study triggered an array of neuroendocrine responses similar to those previously reported (21). Changes in the thyroid $\left(\mathrm{FT}_{3}\right.$ and $\left.\mathrm{FT}_{4}\right)$, corticotropic (cortisol) and somatotropic axes (GH and IGF-1) paralleled the severity of the energy deficit and were therefore more pronounced (but not significantly different) in the PEG-OB group, which lost significantly more weight. In addition, PEG-OB treatment did not prevent the inhibition of the sympathetic nervous system activity, which normally occurs during energy restriction. The suppression in several reproductive hormones (LH, PRL, and estimated free testosterone with the exception of FSH) tended to be reduced in the PEG-OB treated group but failed to reach significance. However, after adjustment for weight loss using multiple linear regression, the drop in mean $\mathrm{LH}$ levels was attenuated in the PEG-OB group compared with the placebo group.

A recent study reported reversal of the effects of sustained weight-reduction on circulating concentrations of thyroid hormones $\left(\mathrm{T}_{3}\right.$ and $\mathrm{T}_{4}$ but not TSH) in four subjects by a low dose of exogenous leptin (22). In contrast, our study failed to demonstrate an effect of leptin administration on the weight-loss decline in $\mathrm{FT}_{3}$. The findings of this study are in line with the characteristics of two human syndromes associated with absent or very low leptin levels.

Patients with total leptin deficiency or non-functional leptin receptors have been shown to be markedly hyperphagic and the majority of these rare very obese patients identified until now fail to attain normal adult reproductive capabilities (23-25). Daily s.c. recombinant human leptin treatment of a young very obese girl with a mutated $o b$ gene caused rapid and progressive reductions in body weight as a result of decreased appetite and food-seeking behavior. Furthermore, after 1 year of treatment with a low dose of leptin, the appearance of pulsatile nocturnal changes in LH was noted, which suggested the onset of early puberty (26).

Four months of leptin replacement in seven female patients with severe lipodystrophy and leptin deficiency improved menstrual abnormalities and low 
Table 3 Changes in mean (5-h) serum concentrations (pools) for all subjects.

\begin{tabular}{|c|c|c|c|c|}
\hline & \multicolumn{2}{|c|}{ Placebo $(n=10)$} & \multicolumn{2}{|c|}{ PEG-OB $(n=12)$} \\
\hline & Day - 14 & Day 25 & Day - 14 & Day 25 \\
\hline Cortisol (nmol/l) & $204.2 \pm 24.0$ & $240.8 \pm 19.4$ & $214.5 \pm 17.6$ & $241.8 \pm 18.4$ \\
\hline $\mathrm{GH}(\mathrm{mU} / \mathrm{l})$ & $0.40 \pm 0.12$ & $1.75 \pm 0.41^{\mathrm{b}}$ & $0.55 \pm 0.21$ & $2.17 \pm 0.44^{b}$ \\
\hline $\mathrm{TSH}(\mathrm{mU} / \mathrm{l})$ & $1.24 \pm 0.07$ & $1.09 \pm 0.14$ & $1.18 \pm 0.14$ & $1.09 \pm 0.15$ \\
\hline PRL (U/I) & $0.121 \pm 0.010$ & $0.101 \pm 0.013^{a}$ & $0.135 \pm 0.013$ & $0.126 \pm 0.015$ \\
\hline $\mathrm{LH}(\mathrm{U} / \mathrm{I})$ & $3.72 \pm 0.75$ & $3.07 \pm 0.70^{\mathrm{a}}$ & $3.63 \pm 0.47$ & $3.44 \pm 0.39$ \\
\hline FSH (U/I) & $4.28 \pm 1.45$ & $4.01 \pm 1.46$ & $3.71 \pm 0.72$ & $3.35 \pm 0.48$ \\
\hline Total testosterone $(\mathrm{nmol} / \mathrm{l})$ & $19.45 \pm 2.03$ & $19.08 \pm 1.26$ & $19.33 \pm 1.06$ & $22.17 \pm 1.02^{\mathrm{a}}$ \\
\hline SHBG $(\mathrm{nmol} / \mathrm{l})$ & $20.2 \pm 2.4$ & $38.4 \pm 6.3^{b}$ & $20.8 \pm 1.8$ & $38.5 \pm 2.9^{c}$ \\
\hline Albumin $(g / l)$ & $40.8 \pm 0.6$ & $40.3 \pm 0.9$ & $41.3 \pm 0.5$ & $40.5 \pm 0.7$ \\
\hline Free testosterone† (pmol/l) & $438.4 \pm 32.1$ & $295.7 \pm 20.1^{b}$ & $432.2 \pm 25.3$ & $345.5 \pm 20.5^{b}$ \\
\hline
\end{tabular}

Data are presented as means \pm S.E.M.

†Free testosterone was calculated from plasma total testosterone, SHBG and albumin (see Subjects and methods section).

For differences compared to baseline (day -14 ): ${ }^{\mathrm{a}} P<0.05,{ }^{\mathrm{b}} P<0.01,{ }^{\mathrm{c}} P<0.001$.

estradiol levels and corrected the blunted LH response to luteinizing hormone-releasing hormone. No clinical or key regulatory effects of treatment were observed on thyroid or adrenocortical function (27).

Taken together, our results seem to support the hypothesis that the reduction in leptin is one of the factors that may be responsible for the fasting-induced inhibition of the reproductive axis and subsequent impaired fertility in humans $(28,29)$.

Several limitations of our study are of note that could account for the limited effect of leptin observed in this study. The lowest leptin levels reached in the placebo group in this study are still higher than the leptin levels found in the syndromes mentioned above. Furthermore, reproductive function is known to continue in males under limited energy availability in which it is completely blocked in females, suggesting that female reproduction is more sensitive to

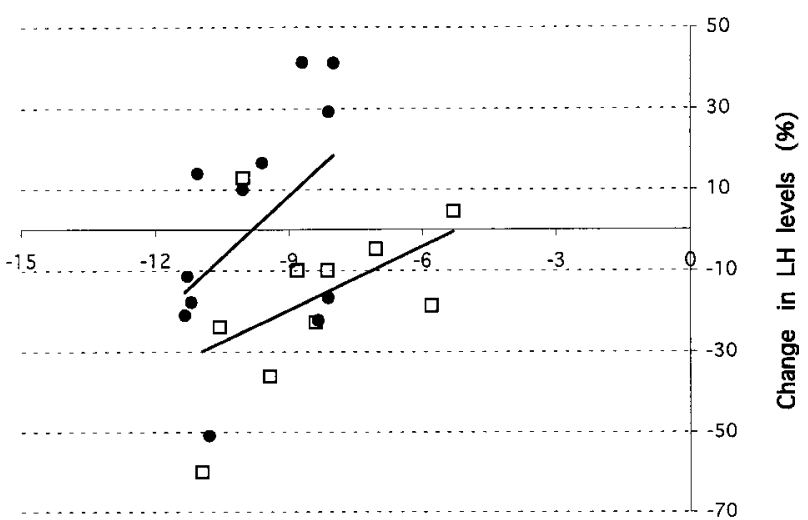

Change in bodyweight (\%)

Figure 1 Percentage change in 5-h mean LH concentrations as a function of percentage change in weight plotted for the PEG-OB group (๑) and placebo group ( $\square$ ). The regression line of the PEG-OB group is significantly different from the regression line of the placebo group (Multiple-linear-regression analysis: $P=0.03$ ). nutritional deprivation $(30,31)$. Both observations could account for the limited effect of leptin therapy on reproductive hormones found in this study with severe energy-restricted overweight males. Also the serum leptin levels achieved in this pharmacological study are supraphysiological. Recent studies suggest that the threshold for the various responses to leptin is set at different levels. Some evidence suggests that especially the effects on neuroendocrine function elicited by hyperleptinemia might differ from those caused by leptin in the physiological range $(32,33)$. Finally, more subtle effects on these dynamic neuroendocrine axes might have been revealed by direct measurements of diurnal variations or the pulsatility of secretory patterns.

In conclusion, we demonstrated that although weekly $80 \mathrm{mg}$ s.c. PEG-OB administration to severe energy-restricted healthy overweight men led to significant additional weight loss after 6 weeks, it did not reverse the fasting-induced changes in the thyroid, corticotropic, somatotropic axes, and sympathetic nervous system activity. However, the drop in mean LH levels when adjusted for weight loss was attenuated in the PEG-OB group compared with the placebo group. This result suggests that a reduced level of leptin accompanying food restriction might be a component of the fasting-induced neuroendocrine inhibition of the human reproductive axis.

\section{Acknowledgements}

We thank Hoffmann-La Roche Inc. for kindly providing PEG-OB. We also wish to express our sincere appreciation to Inge van Ierssel, Marja van der Hulst and Fiona Ong for their commitment and assistance during this study. Finally, we greatly acknowledge the co-operation, patience, and contributions of all our subjects. 


\section{References}

1 Schwartz MW, Dallman MF \& Woods SC. Hypothalamic response to starvation: implications for the study of wasting disorders. American Journal of Physiology 1995269 R949-R957.

2 Flier JS. Clinical review 94: What's in a name? In search of leptin's physiologic role. Journal of Clinical Endocrinology and Metabolism 199883 1407-1413.

3 Zhang Y, Proenca R, Maffei M, Barone M, Leopold L \& Friedman JM. Positional cloning of the mouse obese gene and its human homologue. Nature 1994372 425-432.

4 Halaas JL, Gajiwala KS, Maffei M, Cohen SL, Chait BT, Rabinowitz $\mathrm{D}$ et al. Weight-reducing effects of the plasma protein encoded by the obese gene. Science 1995269 543-546.

5 Pelleymounter MA, Cullen MJ, Baker MB, Hecht R, Winters D, Boone $\mathrm{T}$ et al. Effects of the obese gene product on body weight regulation in ob/ob mice. Science $1995269540-543$.

6 Considine RV, Sinha MK, Heiman ML, Kriauciunas A, Stephens TW, Nyce MR et al. Serum immunoreactive-leptin concentrations in normal-weight and obese humans. New England Journal of Medicine $1996334292-295$.

7 Ahima RS, Prabakaran D, Mantzoros C, Ou D, Lowell B, Maratos Flier E et al. Role of leptin in the neuroendocrine response to fasting. Nature $1996 \mathbf{3 8 2} 250-252$.

8 Boden G, Chen X, Mozzoli M \& Ryan I. Effect of fasting on serum leptin in normal human subjects. Journal of Clinical Endocrinology and Metabolism 199681 3419-3423.

9 Legradi G, Emerson CH, Ahima RS, Flier JS \& Lechan RM. Leptin prevents fasting-induced suppression of prothyrotropin-releasing hormone messenger ribonucleic acid in neurons of the hypothalamic paraventricular nucleus. Endocrinology 1997138 2569-2576.

10 Finn PD, Cunningham MJ, Pau KY, Spies HG, Clifton DK \& Steiner RA. The stimulatory effect of leptin on the neuroendocrine reproductive axis of the monkey. Endocrinology $1998 \quad 139$ $4652-4662$.

11 Lado Abeal J, Lukyanenko YO, Swamy S, Hermida RC, Hutson JC \& Norman RL. Short-term leptin infusion does not affect circulating levels of LH, testosterone or cortisol in food-restricted pubertal male rhesus macaques. Clinical Endocrinology 199951 $41-51$.

12 Lado Abeal J, Hickox JR, Cheung TL, Veldhuis JD, Hardy DM \& Norman RL. Neuroendocrine consequences of fasting in adult male macaques: effects of recombinant rhesus macaque leptin infusion. Neuroendocrinology 200071 196-208.

13 Heymsfield SB, Greenberg AS, Fujioka K, Dixon RM, Kushner R, Hunt $\mathrm{T}$ et al. Recombinant leptin for weight loss in obese and lean adults-A randomized, controlled, dose-escalation trial. Journal of the American Medical Association $1999 \mathbf{2 8 2}$ $1568-1575$.

14 Nucci ML, Shorr R \& Abuchoweski A. The therapeutic value of poly(ethylene-glycol)-modified proteins. Advanced Drug Delivery Reviews 19916 133-151.

15 Kahler A, Geary N, Eckel LA, Campfield LA, Smith FJ \& Langhans W. Chronic administration of $\mathrm{OB}$ protein decreases food intake by selectively reducing meal size in male rats. American Journal of Physiology 1998275 R180-R185.

16 Hukshorn CJ, Saris WHM, Westerterp Plantenga MS, Farid AR, Smith FJ \& Campfield LA. Weekly subcutaneous pegylated recombinant native human leptin (PEG-OB) administration in obese men. Journal of Clinical Endocrinology and Metabolism 2000 85 4003-4009.

17 Swinkels LM, Ross HA \& Benraad TJ. A symmetric dialysis method for the determination of free testosterone in human plasma. Clinica Chimica Acta 1987165 341-349.

18 Swinkels LM, Meulenberg PM, Ross HA \& Benraad TJ. Salivary and plasma free testosterone and androstenedione levels in women using oral contraceptives containing desogestrel or levonorgestrel. Annals of Clinical Biochemistry 198825 354-359.

19 Dunn JF, Nisula BC \& Rodbard D. Transport of steroid hormones: binding of 21 endogenous steroids to both testosterone-binding globulin and corticosteroid-binding globulin in human plasma. Journal of Clinical Endocrinology and Metabolism 198153 58-68.

20 Hukshorn CJ. Westerterp Plantenga MS \& Saris WHM. Pegylated human recombinant leptin (PEG-OB) causes additional weight loss in severe energy-restricted overweight men. American Journal of Clinical Nutrition $2003 \mathbf{7 7} 771-776$.

21 Friedl KE, Moore RJ, Hoyt RW, Marchitelli LJ, Martinez Lopez LE \& Askew EW. Endocrine markers of semi-starvation in healthy lean men in a multistressor environment. Journal of Applied Physiology 200088 1820-1830.

22 Rosenbaum M, Murphy EM, Heymsfield SB, Matthews DE \& Leibel RL. Low dose leptin administration reverses effects of sustained weight-reduction on energy expenditure and circulating concentrations of thyroid hormones. Journal of Clinical Endocrinology and Metabolism 200287 2391-2394.

23 Montague CT, Farooqi IS, Whitehead JP, Soos MA, Rau H, Wareham NJ et al. Congenital leptin deficiency is associated with severe early-onset obesity in humans. Nature $1997 \mathbf{3 8 7}$ 903-908.

24 Ozata M, Ozdemir IC \& Licinio J. Human leptin deficiency caused by a missense mutation: multiple endocrine defects, decreased sympathetic tone, and immune system dysfunction indicate new targets for leptin action, greater central than peripheral resistance to the effects of leptin, and spontaneous correction of leptin-mediated defects. Journal of Clinical Endocrinology and Metabolism 199984 3686-3695.

25 Clement K, Vaisse C, Lahlou N, Cabrol S, Pelloux V, Cassuto D et al. A mutation in the human leptin receptor gene causes obesity and pituitary dysfunction. Nature 1998392 398-401.

26 Farooqi IS, Jebb SA, Langmack G, Lawrence E, Cheetham $\mathrm{CH}$, Prentice AM et al. Effects of recombinant leptin therapy in a child with congenital leptin deficiency. New England Journal of Medicine 1999341 879-884.

27 Oral EA, Ruiz E, Andewelt A, Sebring N, Wagner AJ, Depaoli AM et al. Effect of leptin replacement on pituitary hormone regulation in patients with severe lipodystrophy. Journal of Clinical Endocrinology and Metabolism 200287 3110-3117.

28 Himms Hagen J. Physiological roles of the leptin endocrine system: differences between mice and humans. Critical Reviews in Clinical Laboratory Sciences 199936 575-655.

29 Hileman SM, Pierroz DD \& Flier JS. Leptin, nutrition, and reproduction: timing is everything. Journal of Clinical Endocrinology and Metabolism 200085 804-807.

30 Hamilton GD \& Bronson FH. Food restriction and reproductive development: male and female mice and male rats. American Journal of Physiology 1986250 R370-R376.

31 Lado-Abeal J, Prieto D, Lorenzo M, Lojo S, Febrero M, Camarero E et al. Differences between men and women as regards the effects of protein-energy malnutrition on the hypothalamic-pituitarygonadal axis. Nutrition $199915351-358$.

32 Yu WH, Kimura M, Walczewska A, Karanth S \& McCann SM. Role of leptin in hypothalamic-pituitary function. PNAS 1997 94 1023-1028.

33 Ahima RS, Kelly J, Elmquist JK \& Flier JS. Distinct physiologic and neuronal responses to decreased leptin and mild hyperleptinemia. Endocrinology 1999140 4923-4931.

Received 23 October 2002

Accepted 10 March 2003 